\title{
Penanaman Nilai Karakter Anak Usia Dini Pada Model Pembelajaran Bcct (Beyond Centers And Circle Time) Di TK Pembina Sukaramai, Kecamatan Kerajaan, Kabupaten Pakpak Baharat
}

\section{Elya Siska Anggraini}

Dosen Program Studi PG PAUD FIP UNIMED

Jln. Williem ISKANDAR Pasar V Medan Estate, Medan, Sumatera Utara, 20371

Email : elyasiskaanggraini@unimed.ac.id

Abstrak : Penelitian ini bertujuan untuk mengetahui proses pembelajaran pendidikan anak usia dini melalui model pembelajaran BCCT (Beyond Centers and Circle Time) dalam menanamkan pendidikan karakter di Taman KanakKanak Pembina Sukaramai, Kabupaten Pakpak Bharat Sumatera Utara. Jenis penelitian yang digunakan adalah kualitatif dengan pendekatan etnografi. Pemilihan subyek menggunakan purposive sampling, dilanjutkan dengan Snow Ball Sampling. Pengumpulan data pada penelitian ini menggunakan metode observasi, wawancara dan dokumentasi. Keberhasilan penanaman pendidikan karakter melalui model pembelajaran BCCT (Beyond Centers and Circle Time) dapat diketahui dengan melihat hasil penilaian yang telah dilakukan oleh guru.

Kata kunci : Pembelajaran PAUD, Model Pembelajaran BCCT, Pendidikan Karakter

\section{PENDAHULUAN}

Pendidikan Nasional bertujuan untuk mengembangkan dan membentuk watak serta peradaban bangsa yang bermartabat dalam rangka mencerdasakan kehidupan bangsa, serta mengembangkan peserta didik agar menjadi manusia yang beriman dan bertaqwa kepada Tuhan Maha Esa, berakhak mulia, sehat bermulia, cakap, kreatif, mandiri dan bertanggung jawab. Menurut Wibowo, ruang lingkup kurikulum di Taman Kanak-kanak dan RA diarahkan pada aspek perkembangan anak usia dini diantaranya: 1) moral dan nilai-nilai agama, 2) sosial emosional dan kemandirian, 3) kemampuan berbahasa, 4) kognitif, 5) fisik dan motorik, 6) seni budaya (Wibowo, 2012). Berdasarkan Standar Kompetensi tersebut, maka menumbuhkan karakter anak usia sejak di PAUD adalah langkah yang tepat. Melalui langkah tersebut diharapkan karakter sudah menjadi bagian dari diri anak usia dini. 
Ruqoyah menjelaskan bahwa untuk meningkatkan mutu pendidikan anak usia dini pemerintah menerapkan salah satu program yang dinamakan program pendidikan karakter. Program pendidikan karakter menerapkan beberapa aspek penanaman pengetahuan, kecintaan dan penanaman perilaku kebaikan menjadi sebuah pola/kebiasaan (Ruqoyah, 2016). Pandangan Ki Hajar Dewantara terkait pendidikan karakter antara lain: 1) pendidikan karakter merupakan salah satu bagian yang tidak terpisahkan dalam sistem pendidikan nasional yang diberikan sejak usia 4-21 tahun; 2) Pendidikan karakter membentuk mental atau sikap yang baik dan menghilangkan mental atau perilaku buruk (sikap jujur, disiplin, bertanggung jawab, demokratis, tidak mementingkan diri sendiri, berani, rela berkorban, tidak merusak, tidak menyakiti orang lain, hidup sehat dan bersih, hormat kepada orang tua, toleran, empati, dan cinta tanah air; 3) pendidikan karakter bagi anak usia dini dapat dilakukan terutama oleh orang tua dan guru melalui pembiasaan atau percontohan dalam berbagai kegiatan pembelajaran bercerita, menggambar, bermain dengan alat permainan tradisional, menyulam, bernyanyi (Maspinal, 2013).

Untuk meningkatkan efisiensi pembelajaran, pemerintah mengadopsi salah satu model pembelajaran yaitu model pembelajaran BCCT (Beyond Centers and Circle Time) (Ruqoyah, 2016). Lebih lanjut, Palupi menjelaskan bahwa BCCT atau Beyond Centers and Circle Time merupakan metode pembelajaran yang sering disebut SELI atau Sentra dan Lingkaran. Metode ini merupakan pengembangan dari metode Montessori, High Scope dan Reggio Emilio yang dikembangkan oleh CCCRT atau Creative Center for Childhood Research and Training, Florida, USA dimana konsep belajarnya guru menghadirkan dunia nyata dalam kelas untuk mendorong muridmuridnya membuat hubungan antara pengetahuan yang dimiliki dengan penerapannya di kehidupan seharihari (Samad \& Alhadad, 2016). Lebih lanjut Sujiono menjelaskan bahwa model pembelajaran BCCT (Beyond Centers and Circle Time) adalah suatu metode atau pendekatan dalam penyelenggaraan pendidikan anak usia dini yang merupakan perpaduan antara teori dan praktik (Sujiono, 2009).

Tujuan pendekatan dari BBCT atau Beyond Center and Circle Time yaitu : 1) Melejitkan potensi kecerdasan anak : kecerdasan sebagai kemampuan untuk mememcahkan masalah dan menciptakan produk yang mempunyai nilai 
buadaya; 2) Penanaman nilai-nilai dasar ; anak merupakan individu yang baru menggenal dunia dan belum mengetahui tata krama, sopan santun, aturan, norma dan sebagainya. Anak perlu dibimbing agar mampu memahami berbagai hal. Usia dini merupakan saat yang sangat berharga untuk menananamkan nilai-nilai dasar dalam kehidupan yang meliputi: nilai-nilai nasionalisme, nilai-nilai agama, nilai-nilai etika, nilai-nilai moral dan nilainilai sosial; 3) pengembangan kemampuan dasar (Samad \& Alhadad, 2016).

\section{KAJIAN TEORI}

BCCT adalah pendekatan yang dikembangkan berdasarkan hasil kajian teoritik dan pengalaman empirik oleh Creative Center for Childhood Research Training (CCCRT) di Florida USA, dan dilaksanakan di Creative Pre School Florida, USA selama lebih dari 25 tahun, baik untuk anak normal maupun anak dengan kebutuhan khusus. BCCT merupakan pengembangan dari pendekatan Montessori, HighScope, dan Reggio Emilio. (Kuniarti, 2008) Istiqomah (2009: 21) mengemukakan bahwa tujuan dari model pembelajaran BCCT adalah untuk merangsang seluruh aspek kecerdasan anak (multiple intelligent) melalui bermain terarah dan diciptakannya setting pembelajaran yang merangsang anak untuk saling aktif, kreatif, dan terus berfikir dengan menggali pengalamannya sendiri (bukan sekedar mengikut perintah, meniru atau menghafal).

Menurut Latif dkk, terdapat tujuh sentra yang dikembangkan oleh Dr. Pamela Phelps, yaitu 1) sentra persipan, 2) sentra balok, 3) sentra peran besar, 4) sentra peran kecil, 5) sentra bahan alam, 6) sentra seni dan 7) sentra musik. Kemudian di Indonesia dikembangkan menjadi enam sentra yaitu: 1) sentra persiapan, 2) sentra balok, 3) sentra bahan alam, 4) sentra seni, 5) sentra main peran besar dan 6) sentra main peran kecil (Latif, Zulkhairina, Zubaidah, \& Muhammad Afandi, 2013). Sedangkan menurut Kusumandari dan Istyarini, implementasi pendidikan karakter melalui pembelajaran e-learning dan berbagai kecerdasan dapat menggunakan 10 sentra, yaitu: 1) sentra pusat persiapan, 2) sentra persiapan, 3) sentra alam padat, 4) sentra alam cair, 5) sentra IMTAQ, 6) sentra balok, 7) sentra main peran, 8) sentra bahasa Inggris, 9) sentra seni, dan 10) sentra tubuh (Kusumandari \& Istyarini, 2015). 
Permasalahan pendidikan karakter di Indonesia, dilihat dari sudut pandang peneliti perlu adanya model pembelajaran yang mampu menanamkan pendidikan karakter pada anak usia dini. Di dalam penelitian ini, akan dibahas penggunaan metode pembelajaran BCCT untuk menanamkan nilai-nilai pendidikan karakter anak usia dini. Menurut Istiqomah, metode BCCT ini diyakini mampu merangsang seluruh aspek kecerdsasan anak melalui bermain yang terarah, setting pembelajaran yang mampu merangsang anak selalu aktif, kreatif, dan terus berpikir dengan menggali pengalamannya sendiri. Anak didorong untuk bermain di sentra-sentra kegiatan, sedangkan pendidik berfungsi sebagai perancang, pendukung, dan penilai kegiatan anak. Pembelajarannya bersifat individual, sehingga rancangan, dukungan, dan penilaiannya pun disesuaikan dengan tingkat perkembangan kebutuhan setiap anak (Ma'rifah \& Muthmainnah, 2015). Oleh sebab itu, dilakukan penelitian untuk mendeskripsikan penggunaan model pembelajaran BCCT dalam menanamkan pendidikan karakter bagi anak usia dini.

\section{METODOLOGI PENELITIAN}

Adapun jenis penelitian yang digunakan dalam penggunaan model pembelajaran BCCT dalam menanamkan pendidikan karakter bagi anak usia dini ini adalah dengan kualitatif dengan pendekatan etnografi yang bertujuan untuk menjelaskan dan menganalisis kondisi pembelajaran dengan menggunakan metode pembelajaran sentra dalam menanamkan nilai-nilai karakter di TK Pembina Sukaramai, Kecamatan Kerajaan Kabupaten Pakpak Bharat. Pemilihan subyek dalam penelitian ini menggunakan purposive sampling, dilanjutkan dengan menggunakan Snow Ball Sampling (Patilima, 2010), yaitu pemilihan sample dengan pertimbangan 1) subyek penelitian adalah anak usia dini yang terlibat langsung dalam proses pembelajaran dengan metode sentra, 2) informan dalam penelitian ini merupakan pihak yang menguasai permasalahan berkenan memberikan informasi dan data yaitu guru dan kepala sekolah TK Pembina Sukaramai, Kecamatan Kerajaan Kabupaten Pakpak Bharat.

Penggalian informasi pada penelitian ini menggunakan metode observasi, wawancara dan dokumentasi. Metode observasi digunakan untuk mengamati 
proses belajar mengajar yang berlangsung dengan menerapkan metode sentra dalam menanamkan pendidikan sentra. Pada kegiatan ini, peneliti menggunakan panduan observasi dan catatan lapangan sesuai dengan kegiatan yang diteliti. Metode wawancara pada subyek penelitian untuk mengetahui bagaimana penerapan metode sentra dalam menanamkan nilainilai pendidikan karakter. Metode Dokumentasi yakni mnengumpulkan dokumen-dokumen RPPM / Rencana Pelaksanaan Pembelajaran Mingguan dan RPPH / Rencana Pelaksanaan Pembelajaran Harian tentang nilai-nilai penidikan karakter di Taman Kanak-kanak Pembina Sukaramai Kecamatan Kerajaan Kabupaten Pakpak Bharat.

\section{HASIL DAN PEMBAHASAN}

Pada awal tahun ajaran baru sekolah selalu menyusun rencana pembelajaran berupa program tahunan, program semester, rencana program pembelajaran mingguan dan rencana program pembelajaran harian yang disesuaikan dengan tema, subtema, aspek-aspek kemampuan anak dan nilainilai pendidikan karakter. Hal ini sesuai dengan perencanaan yang dilakukan oleh Taman Kanak-kanak Pembina Sukaramai, Kecamatan Kerajaan, Kabupaten Pakpak Bharat. Kegiatan pembelajaran di TK Pembina Sukaramai Kecamatan Kerajaan Kabupaten Pakpak Bharat ini menerapkan model pembelajaran BCCT atau sering disebut model pembelajaran sentra. Pada TK ini menggunakan tujuh (7) sentra, yang terdiri dari: 1) sentra persiapan, 2) sentra balok, 3) sentra main peran, 4) sentra seni kreativitas, 5) sentra masak, 6) sentra bahan alam, dan 7) sentra musik. Kegiatan pembelajaran terbagi menjadi tiga, yaitu: kegiatan awal, kegiatan inti dan kegiatan penutup.

Kegiatan awal merupakan rangkaian aktivitas yang menarik dan menyenangkan bagi anak dimulai dari anak datang ke sekolah disambut guru, kemudian anak diajak guru untuk berbaris di halaman sekolah, salah seorang guru mememimpin dan guru lain beserta peserta didik mengikuti gerakan mootik kasar dan bernyanyi, kegiatan ini berlangsung kurang lebih 25 menit. Setelah kegiatan awal selesai semua murid berbaris membentuk kereta-keretan mengikuti guru untuk masuk kelas sentra. 
Kegiatan Inti merupakan kegiatan pembelajaran di sentra. Sebelum masuk di kegiatan inti guru dan peserta didik duduk melingkar, guru memberikan salam kepada semua peserta didik, guru mengabsen peserta didik, guru meminta peserta didik untuk memperhatikan siapa yang tidak hadir, berdoa bersama, guru menyampaikan tema kegiatan pembelajaran yang akan dilakukan sesuai dengan kehidupan seharihari, guru mengenalkan semua alat permainan yang telah dipersipakan dan menceritakan permainan yang akan dilakukan oleh peserta didik, guru menyampaikan aturan main, setelah peserta didik siap bermain, guru mempersilakan peserta didik untuk main. Guru berkeliling di antara peserta didik yang bermain yakni memberikan contoh cara bermain bagi peserta didik yang belum mampu dan memberikan pujian pada permainan yang telah dilakukan, selain itu guru juga mencatat hasil perkembangan peserta didik dan mengumpulkan hasil karya peserta didik selama satu semester dalam partofolio.

Kegitan penutup merupakan kegiatan yang memberikan pengalaman dan mengingat kembali. Guru memberitahu kepada peserta didik 5 menit sebelum kegiatan berakhir, guru memberitahu saatnya membereskan semua alat main, apabila peserta didik sudah merapikan alat main, peserta didik dan guru duduk melingkar, guru menanyakan pada setiap peserta didik tentang kegiatan main yang telah dilakukan / recalling, hal ini dilakukan untuk melatih daya ingat peserta didik dan pengalaman mainnya, selanjutnya guru mengajak peserta didik untukk cuci tangan, berdoa, makan siang dan pulang.

Dari hasil wawancara dan pengamatan yang telah dilakukan dapat disimpulkan bahwa pada saat kegiatan pembelajaran diawali dengan guru mensetting lingkungan main dan mengajak anak untuk melakukan kegiatan sebelum bermain. Kegiatan pembelajaran diawali dengan sapaan, nyanyian, membahas tema, dan topik. Anak bermain di area-area main yang sudah disetting oleh guru. Kegiatan diakhiri dengan kegiatan recalling, memberikan kesempatan kepada semua anak untuk menceritakan pengalaman main secara bergiliran melalui tanya jawab atau bercerita. Anak menjadi pembelajar yang aktif selama proses pembelajaran. Kegiatan disetting oleh guru melalui area main di sentra-sentra dengan konsep tematik. Adapun nilai-nilai pendidikan karakter yang ditanamkan pada sentra yaitu : Sentra persiapan fokus pada kesempatan 
anak untuk mengurutkan, mengklasifikasikan, membuat pola-pola dan mengorganisasikan alat-alat dan bahan kerja, termasuk persiapan membaca, menulis dan berhitung. Adapapun nilai pendidikan karakter yang ditanamkan adalah Jujur, Gemar Membaca, Semangat Kebangsaan, Cinta Tanah Air, Sentra balok membantu anak dalam meningkatkan kemampuan berkonstruksi mereka dari membuat susunan garis lurus ke atas ke representasi nyata dan dari bermain sendiri ke kemampuan bekerja dalam kelompok kecil, merencanakan dan membangun. Nilai pendidikan karakter yang ditanamkan yaitu disiplin dan tanggung jawab.

Menurut hasil pengamatan yang dilakukan di TK Pembina Sukaramai Kecamatan Kerajaan Kabupaten Pakpak Bharat. terlihat bahwa anak-anak sudah mampu melaksanakan pendidikan karakter dengan baik. Cara menilai dari hasil pelaksanaan pendidikan karakter yaitu melalui pengamatan yang dilakukan secara terus menerus. Terdapat beberapa kategori penilaian yang diberikan guru untuk menilai keberhasilan pendidikan karakter pada anak, antara lain: Belum Muncul, yaitu anak belum menunjukkan perilaku yang diharapkan; Mulai Muncul, yaitu anak mulai menunjukkan perilaku yang diharapkan dengan bantuan guru/orang lain; Muncul, yaitu anak menunjukkan perilaku yang diharapkan tanpa perlu diingatkan; dan Sudah Muncul, yaitu anak menunjukkan perilaku yang diharapkan dan mampu menjadi contoh bagi orang lain.

Berdasarkan hasil penelitian yang telah dilakukan dapat diketahui bahwa kedelapan belas nilai pendidikan karakter yang ditetapkan oleh Kemendikbud mampu ditanamkan dengan mudah pada anak usia dini khususnya di Pembina Sukaramai Kecamatan Kerajaan Kabupaten Pakpak Bharat.melalui model pembelajaran sentra yang terbagi menjadi 7 sentra. Hasil penelitian ini didukung oleh beberapa penelitian yang juga menggunakan model BCCT dalam menanamkan pendidikan karakter. Pertama, penelitian Ruqoyah menunjukkan bahwa terdapat perbedaan hasil antara anak dengan kreativitas rendah dan kreativitas tinggi yang diajar dengan menggunakan model pembelajaran BCCT dan non BCCT (Ruqoyah, 2016). Kedua, penelitian Samad dan Alhadad menunjukkan bahwa penerapan metode pembelajaran sentra dalam penanaman nilai-nilai agama Islam di TK Pembina Sukaramai 
Kecamatan Kerajaan Kabupaten Pakpak Bharat.membuat anak merasa lebih memiliki kesempatan untuk mengekspresikan bakat dan minat (Samad \& Alhadad, 2016). Ketiga, penelitian Maimunah dkk menunjukkan bahwa guru di dalam model pembelajaran sentra mempunyai peranan penting untuk membangun karakter anak melalui komunikasi positif, perancah, pembiasaan, dan konsistensi dalam membangun aturan. Aturan yang dibuat harus disesuaikan berdasarkan aktivitas dan karakter yang dikembangkan oleh sekolah (Maimunah, Aslamiah, \& Suriansyah, 2018).

\section{SIMPULAN}

Model pembelajaran yang digunakan oleh Taman Kanak-kanak Pembina Sukaramai Kecamatan Kerajaan, Kabupaten Pakpak Bharat menggunakan SELI (Metode Sentra dan Lingkaran) atau sering disebut model pembelajaran sentra. Kegiatan dimulai dengan jurnal pagi yang menyenangkan kemudian masuk pada kegiatan inti yakni bermain di sentra. Tema dibahas oleh guru sebelum bermain kemudian kegiatan ditutup dengan melakukan recalling, dalam proses pembelajaran yang telah dilakukan menanamkan nilai-nilai pendidikan karakter. Dengan menggunakan model pembelajaran Sentra, pendidikan karakter dapat ditanamkan pada anak usia dini dengan tepat.

\section{DAFTAR PUSTAKA}

Sujiono, Y. N. (2009). Konsep Dasar Pendidikan Anak Usia Dini. Jakarta: Indeks.

Wibowo, A. (2012). Pendidikan Karakter Usia Dini ( Strategi Membangun Karakter di Usia Emas). Yogyakarta: Pustaka Pelajar.

Ma'rifah, U., \& Muthmainnah, A. (2015). Metode Pembelajaran BCCT dalam Mengembangkan Nilai Moral Pendidikan Karakter Anak Usia Dini. Jurnal PG-PAUD Trunojoyo, 2(2), 117-124.

Ruqoyah, A. (2016). Pengaruh Model Pembelajaran Beyond Centers and Circle Times (BCCT) dan Kemandirian Terhadap Kreativitas. Jurnal Pendidikan Usia Dini, 10(1), 81-98.

Samad, F., \& Alhadad, B. (2016). Implementasi Metode Beyond Center and Circle Time (BCCT) dalam Upaya Penanaman Nilai-Nilai Agama Islam di Kelompok B Taman KanakKanak Khalifah Kota Ternate. Jurnal Pendidikan Usia Dini, 10(2). 